\title{
Low-cycle Fatigue and Fracture Behaviour of $9 \%$ Ni Steel Flux Cored Arc Welding joint at Cryogenic Temperature
}

\author{
Weidong $\mathrm{Mu}^{1}$, Yuzhang $\mathrm{Li}^{1}$, Yan $\mathrm{Cai}^{1,2, *}$, and Min Wang ${ }^{1,2}$ \\ ${ }^{1}$ Shanghai Key Laboratory of Materials Laser Processing and Modification, Shanghai Jiao Tong University, Shanghai, 200240, China \\ ${ }^{2}$ Collaborative Innovation Center for Advanced Ship and Deep-Sea Exploration, Shanghai, 200240, China
}

\begin{abstract}
In the present work, low-cycle fatigue (LCF) test and crack tip opening displacement (CTOD) test were performed for 9\% Ni steel flux cored arc welding (FCAW) joint at room temperature (296 K) and cryogenic temperature $(80 \mathrm{~K})$. At cryogenic temperature, the strain amplitude had a far greater impact on fatigue life of $9 \% \mathrm{Ni}$ steel welded joint and it decreased dramatically lead to a significant increase in fatigue life. It was found that most fracture initiation of joints located in fusion area at room temperature, while it occurred in weld seam at low temperature. The fracture toughness of weld seam was higher than that of fusion zone no matter the testing temperature. The effect of precipitated phase was the true reason. The fatigue cracks propagated in transgranular mode at room temperature, ultimately, and intergranular mode at low temperature in both LCF specimens and CTOD specimens.
\end{abstract}

\section{Introduction}

In recent years, performance of cryogenic material has gained more attention than before. In most cases, the construction of $9 \% \mathrm{Ni}$ steel welded structures service aggressive environments with fluctuating load and cryogenic temperature. Its cryogenic fatigue property and fracture toughness were critical to product safety. Currently, with good efficiency and adaptability the Flux Cored Arc Welding (FCAW) was used for $9 \% \mathrm{Ni}$ steel in LNG tanks and showed good performance [1]. However little research has been done on fatigue property of $9 \%$ $\mathrm{Ni}$ steel welded joint. The microstructure and performance of $9 \% \mathrm{Ni}$ steel joint made by FCAW are still not investigated fully.

Ni-based alloy has been the preferential candidate for $9 \% \mathrm{Ni}$ steel welded structures [2]. Studies in Ni-based alloys, while plentiful, are predominantly focused on fatigue and fracture property at room and high temperature [3-7]. And yet, very little research has addressed that at cryogenic temperature. The weld metal mainly consists of austenite and precipitates. Some researches were carried out on the effects of precipitates in the weld metal of nickel based alloy. [8] studied the deposited metal of $\mathrm{Ni}-\mathrm{Cr}-\mathrm{Mo}-\mathrm{Nb}$ alloy in TIG cold wire welding. They identified that the precipitated phases were Laves phase and complex carbide particles. [9] investigated high-cycle fatigue (HCF) properties at $4 \mathrm{~K}$, $77 \mathrm{~K}$ and $293 \mathrm{~K}$ in forged-INCONEL 718 Nickel-based alloy. It was found that fatigue cracks predominantly initiated from coarse $\mathrm{Nb}$-enriched $\mathrm{MC}$ carbides which seem to lower the high-cycle fatigue strength at cryogenic temperature. [10] investigated the effects of precipitates on at $-196^{\circ} \mathrm{C}$. They found that Laves phases provided a preferential site for crack initiation and propagation. The performance degradation of weld metal had close relationship with the size and volume percentage of Laves particles. [11] found that the carbide located at grain boundary, increased noticeably the incidence of cracks. From this point of view, influences of precipitated phases deserve more attention on the study of fatigue property.

In this paper, the fatigue property and fracture toughness of welded joints of $9 \% \mathrm{Ni}$ steel by FCAW under cryogenic environment were studied. Low cycle fatigue test was used to study the fatigue property of the joint at room temperature $(296 \mathrm{~K})$ and at cryogenic temperature $(80 \mathrm{~K})$.

It was found that the weakest position in the joint was the fusion area at room temperature while weld metal at cryogenic temperature. As a consequence, the fracture toughness of these positions were investigated by using CTOD test. The crack propagation mode in the stable propagation region of LCF and CTOD specimens was observed. The effect of cryogenic environment on the LCF and fracture toughness were invested in the paper.

\section{Material and procedure}

\subsection{Material and welding procedure}

The composition of $9 \% \mathrm{Ni}$ steel (by QT) and filler wire are listed in Table 1. The base metal plates were processed into sizes of $400 \mathrm{~mm}(\mathrm{~L}) \times 200 \mathrm{~mm}(\mathrm{~W}) \times 20$ 
$\mathrm{mm}(\mathrm{H})$. The plate were machined into K-groove configuration and welded along transverse-to-rolling direction by flux cored arc welding (FCAW) processes. The flux-cored wire is DW- 70S, the diameter is $1.2 \mathrm{~mm}$.

Table 1. Chemical composition of $9 \% \mathrm{Ni}$ steel and filler wire (based on $\mathrm{wt} \%$ )

\begin{tabular}{cccccccccccccccccccc}
\hline Sample & $\mathrm{C}$ & $\mathrm{Si}$ & $\mathrm{Mn}$ & $\mathrm{P}$ & $\mathrm{S}$ & $\mathrm{Cu}$ & $\mathrm{Cr}$ & $\mathrm{Ni}$ & $\mathrm{Mo}$ & $\mathrm{Nb}$ & $\mathrm{Al}$ & $\mathrm{V}$ & $\mathrm{Ti}$ & $\mathrm{Fe}$ \\
\hline Base metal & 0.049 & 0.194 & 0.616 & $<0.003$ & 0.0004 & $<0.005$ & 0.014 & 9.02 & 0.076 & - & $0.028<0.005$ & 0.003 Balance \\
DW- 70S & 0.05 & 0.20 & 5.91 & 0.002 & 0.002 & - & 16.8 & 62.6 & 10.2 & 2.0 & - & - \\
\hline
\end{tabular}

Fig. 1. Schematic illustration of test specimens and set-up of LCF and CTOD test

The welding parameter was listed in Table 2.There were two welding passes in top part and two passes in back part, respectively. The interpass temperature was controlled below $100^{\circ} \mathrm{C}$ strictly for all welding processes. The welded joints have met the standard by nondestructive $\mathrm{X}$-ray examination.

Table 2. Welding parameters of $9 \% \mathrm{Ni}$ steel welded joint

\begin{tabular}{ccccc}
\hline Pass & $\begin{array}{c}\text { Voltage } \\
(\mathrm{V})\end{array}$ & $\begin{array}{c}\text { Current } \\
(\mathrm{A})\end{array}$ & $\begin{array}{c}\text { Traveling speed } \\
(\mathrm{cm} / \mathrm{min})\end{array}$ & $\begin{array}{c}\text { Heat input } \\
(\mathrm{KJ})\end{array}$ \\
\hline 1 & 24.0 & 140 & 5 & 40.32 \\
2 & 24.5 & 160 & 10.6 & 22.19 \\
3 & 25.0 & 170 & 10.4 & 24.52 \\
4 & 25.0 & 170 & 8.3 & 30.72 \\
\hline
\end{tabular}

\subsection{Low cycle fatigue test}

In low cycle fatigue test, uniaxial fatigue tests were carried out using MTS 370 fatigue testing system. cylinder specimens with $25 \mathrm{~mm}$ gauge length and $8 \mathrm{~mm}$ diameter were prepared as shown in Fig 1. According to the test standard [12]. Uniaxial strain-controlled was employed. A triangular waveform was selected and the strain ratio was $\mathrm{R}=-1.0$. The strain rate was $3.0 \times 10-3 \mathrm{~s}^{-}$ 1. Different strain amplitudes were chosen from $0.3 \%$ to $0.8 \%$ until the specimen fracture or the maximum load decreases $50 \%$.

Coffin-Manson relationship was used to characterize the low-cycle fatigue behavior [7]. According to the theory, the total strain amplitude consist of the elastic strain amplitude and plastic strain amplitude in cyclic loading:

$$
\begin{gathered}
\Delta \varepsilon_{\mathrm{t}} / 2=\Delta \varepsilon_{\mathrm{p}} / 2+\Delta \varepsilon_{\mathrm{e}} / 2 \\
\Delta \varepsilon_{\mathrm{p}} / 2=\varepsilon_{\mathrm{f}}^{\prime}\left(2 \mathrm{~N}_{\mathrm{f}}\right)^{\mathrm{c}} \Delta \varepsilon_{\mathrm{e}} / 2=\sigma_{\mathrm{f}} / \mathrm{E}\left(2 \mathrm{~N}_{\mathrm{f}}\right)^{\mathrm{b}}
\end{gathered}
$$

Where $\sigma_{\mathrm{f}}^{\prime}$ is the fatigue strength coefficient, $\mathrm{E}$ is the
Young's modulus, $\mathrm{b}$ is the fatigue strength exponent, $\varepsilon_{\mathrm{f}}^{\prime}$ is the fatigue ductility coefficient, $\mathrm{c}$ is the fatigue ductility exponent and $\mathrm{N}_{\mathrm{f}}$ is the number of reversals to fatigue failure.

Ramberg-Osgood equation is used widely to describe the cyclic stress-strain relationship [13]:

$$
\Delta \sigma / 2=K^{\prime}\left(\varepsilon_{\mathrm{p}} / 2\right)^{\mathrm{n}^{\prime}}
$$

Where $\Delta \sigma / 2$ is the mid-life stress amplitude, $\varepsilon_{\mathrm{p}} / 2$ is the mid-life plastic strain amplitude, $\mathrm{K}^{\prime}$ is the cyclic strength coefficient and $\mathrm{n}$ is the cyclic strain hardening exponent.

\subsection{CTOD test}

In precracking process, the precracking frequency was $10 \mathrm{~Hz}$ and the maximum fatigue stress intensity factor applied during the final stages of fatigue crack extension was $25 \mathrm{Mpa} / \mathrm{mm}^{2}$. It was conducted at room temperature.

The notches of CTOD specimens mainly located in weld seam and fusion zone. As shown in Fig 1, the initial crack location of weld seam specimen was the center of the third weld pass (Point A), while that of fusion zone specimen was the fusion line corrispond to the third weld pass (Point B). In three-point bending process, displace control mode with $0.5 \mathrm{~mm} / \mathrm{min}$ was used. In the process conducted a clip-on displacement gage was used to measure the opening displacement of the notch. According to the standard in the BS 7448 standard $[14,15]$. The crack tip opening displacement $\delta$ is composed of elastic displacement $\delta_{e}$ and plastic displacement $\delta_{p}$ ie:

$$
\begin{aligned}
& \delta=\delta_{e}+\delta_{p} \\
& \text { Where } \quad \delta_{e}=\left[\frac{F S}{B W^{1.5}} \cdot f\left(\frac{a_{0}}{W}\right)\right]^{2} \cdot \frac{\left(1-v^{2}\right)}{2 \sigma_{S} E} \\
& \delta_{p}=\frac{0.4\left(W-a_{0}\right) V_{p}}{0.4 W+0.6 a_{0}+z} \\
& f\left(\frac{a_{0}}{W}\right)=\frac{3\left(\frac{a_{0}}{W}\right)^{0.5}\left[1.99-\left(\frac{a_{0}}{W}\right)\left(1-\frac{a_{0}}{W}\right)\left(2.20-\frac{3.93 a_{0}}{W}+\frac{2.7 a_{0}{ }^{2}}{W^{2}}\right)\right]}{2\left(1+\frac{2 a_{0}}{W}\right)\left(1-\frac{a_{0}}{W}\right)^{1.5}}
\end{aligned}
$$

Where, $W$ and $B$ are the width and the thickness of specimen, $z$ is the blade thickness, $F$ is the load, $S$ is the 
span of specimen, $a_{0}$ is the initial length of crack, $E$ is the Young's modulus, $\sigma_{S}$ is the yielding strength of crack tip, $V_{p}$ is the plastic component of crack tip open distance.

All tests were performed isothermally at $296 \mathrm{~K}$ and $80 \mathrm{~K}$. When test was conducted at low temperature, advanced environmental chamber the temperature range of which could be from $-196^{\circ} \mathrm{C}$ to $350^{\circ} \mathrm{C}$. The size of the chamber was $230 \mathrm{~mm}(\mathrm{~L}) \times 230 \mathrm{~mm}(\mathrm{~W}) \times 340 \mathrm{~mm}(\mathrm{H})$. Liquid nitrogen was to adopt to hold cryogenic temperature constant in environmental chamber.

\section{Results and discussion}

\subsection{LCF behaviour}

The fatigue life of joints with different total strain amplitude were presented in Fig 2. It was found that under the same total strain amplitude, the fatigue life increased dramatically with the temperature decreased from $296 \mathrm{~K}$ to $80 \mathrm{~K}$. With the total strain amplitude increased, the increasing amplitude of low-temperature fatigue life reduced ultimately. It dropped from 5.26 times to 0.85 times at $80 \mathrm{~K}$ with the increase of the total strain amplitude from $0.3 \%$ to $0.8 \%$.

The location of the fracture initiation of all joints were observed. It was found that most fracture initiation located in fusion area at room temperature (Fig 3(a)), while it occurred in weld seam at cryogenic temperature as shown in Fig 3(b). It was inferred that the weakest position in the joint was the fusion area while weld metal at cryogenic temperature.

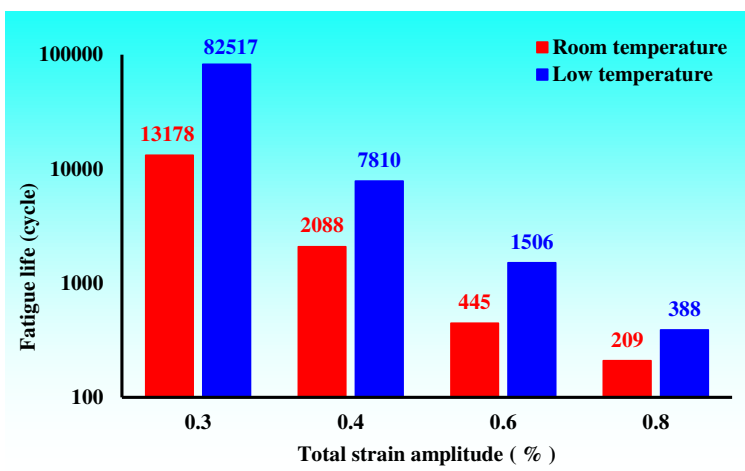

Fig. 2. Mean fatigue life of joints with different total strain amplitude

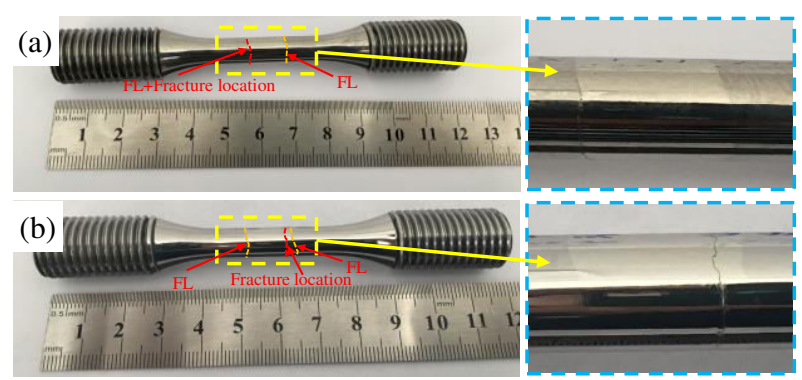

Fig. 3. Fracture location in typical specimen (a) at room temperature and (b) at cryogenic temperature

The parameters of the fatigue life were all obtained in
Table 2 by linear fitting. It was clear that the cyclic strength coefficient $K^{\prime}$ and the cyclic strain hardening exponent $n^{\prime}$ of the joint were both larger at $80 \mathrm{~K}$ than that at $296 \mathrm{~K}$. It was indicated that when the plastic strain amplitude was the same, the strength of the joint at low temperature was larger leading to the better low cycle fatigue property. It was clearly seen that the absolute values fatigue ductility coefficient $\varepsilon^{\prime}$, fatigue ductility exponent $\mathrm{c}$, fatigue strength coefficient $\sigma^{\prime}$, fatigue strength exponent $b$ at cryogenic temperature are greater than that at room temperature, which reflecting quite different plastic and elastic deformation characteristics of joints at different temperature, which could be further explained by the microstructure of different zones.

Table 3. Low-cycle fatigue property parameters of the joint at different temperature

\begin{tabular}{ccc}
\hline Fitting parameters & $296 \mathrm{~K}$ & $80 \mathrm{~K}$ \\
\hline $\begin{array}{c}\text { Cyclic strength coefficient, } \\
\text { K'(MPa) }\end{array}$ & 1127 & 1796 \\
$\begin{array}{c}\text { Cyclic strain hardening } \\
\text { exponent, n' }\end{array}$ & 0.1083 & 0.1238 \\
$\begin{array}{c}\text { Fatigue ductility coefficient, } \\
\varepsilon^{\prime}\end{array}$ & - & - \\
$\begin{array}{c}\text { Fatigue ductility exponent, c } \\
\text { Fatigue strength coefficien, } \\
\sigma^{\prime}(\mathrm{MPa})\end{array}$ & 0.1054 & 0.3481 \\
$\begin{array}{c}\text { Fatigue strength exponent, b } \\
\text { (1004 }\end{array}$ & - & 1664 \\
\hline
\end{tabular}

Fig 4 displayed the stabilized hysteresis loops of LCF tests with different strain amplitude at $296 \mathrm{~K}$ and 80 $\mathrm{K}$. It was found that the stress amplitude increased with increasing total strain amplitude. Under the same total strain amplitude, the load peaks at cryogenic temperature was higher than that at room temperature. The enclosed area was determined by strain amplitude and stress amplitude. Combined with the distribution of elastic and plastic strain amplitude as shown in Fig 4(c) and Fig 4(d). The elastic strain amplitude was the main reason leading to the higher axial stress at cryogenic temperature. Due to higher plastic strain amplitude at room temperature, the enclosed area of the hysteresis loops at $296 \mathrm{~K}$ was much larger than that at $80 \mathrm{~K}$. Plastic strain energy at cryogenic temperature was far less than that at room temperature, resulting in the increase of fatigue life at cryogenic temperature. 

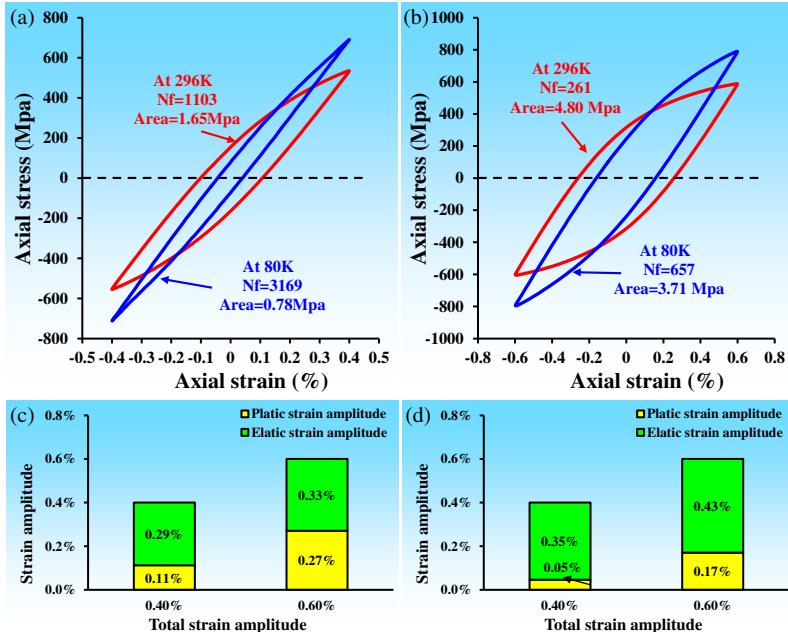

Fig. 4. The cyclic stable hysteresis loops with a total strain amplitude of (a) $0.40 \%$, (b) $0.60 \%$ at $296 \mathrm{~K}$ and $80 \mathrm{~K}$

\subsection{Fracture toughness distribution}

Based on different fracture locations in LCF test, it is necessary to study the fracture toughness of both areas in the joint by CTOD test. Fig 5 shows the CTOD values of both areas at $296 \mathrm{~K}$ and $77 \mathrm{~K}$. It was found that the fracture toughness, represented by the CTOD values, of all regions had a big drop when the temperature drop to $80 \mathrm{~K}$. It decreased $41.9 \%$ in weld seam and $6.4 \%$ in fusion zone respectively. The CTOD value of weld seam was $74.0 \%$ higher than that of fusion zone at $296 \mathrm{~K}$, and it was $7.9 \%$ higher at $80 \mathrm{~K}$. It could be inferred that initial cracks located in fusion zone propagate much easier due to low fracture toughness at room temperature. However at low temperature the fracture toughness in weld zone was very close to that in fusion zone. There are some reasons else lead to the fracture location in weld seam at low temperature.

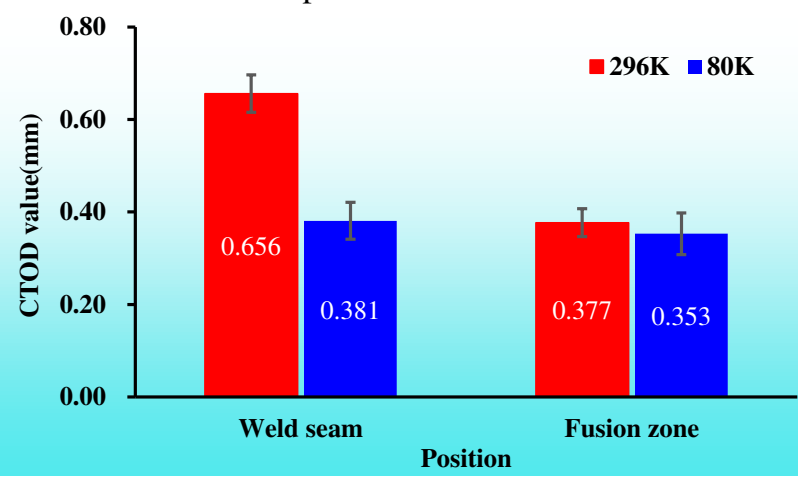

Fig. 5. The CTOD value of the joint at $296 \mathrm{~K}$ and $80 \mathrm{~K}$
Fig 6 shows the representative force-displacement $(\mathrm{F}-\mathrm{V})$ curves of weld seam and fusion zone specimens. The max force of weld seam specimen was lower than that of fusion zone specimen. The max force of specimen tested at $296 \mathrm{~K}$ was lower than that at $80 \mathrm{~K}$. The maximum value of notch opening displacement corresponding to max force was composed of two parts: the plastic part and the elastic part. It was clear that the elastic component increased when temperature dropped into $80 \mathrm{~K}$. It was because that the yield strength of materials increases at low temperature. it takes more force to produce plastic deformation of sample. Different from the elastic part, the plastic part of COD varied between two regions. The COD'S plastic component of weld seam was higher than that of fusion zone both at room temperature and in cryogenic environment.

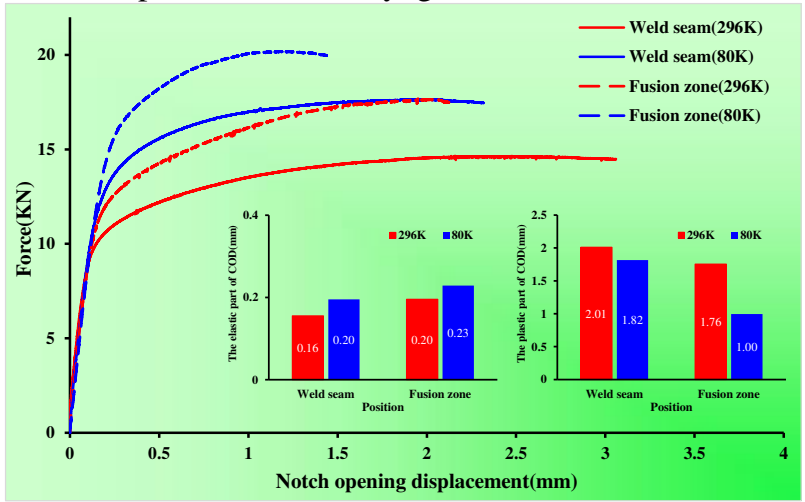

Fig. 6. The force-displacement curves of weld seam and fusion zone specimens

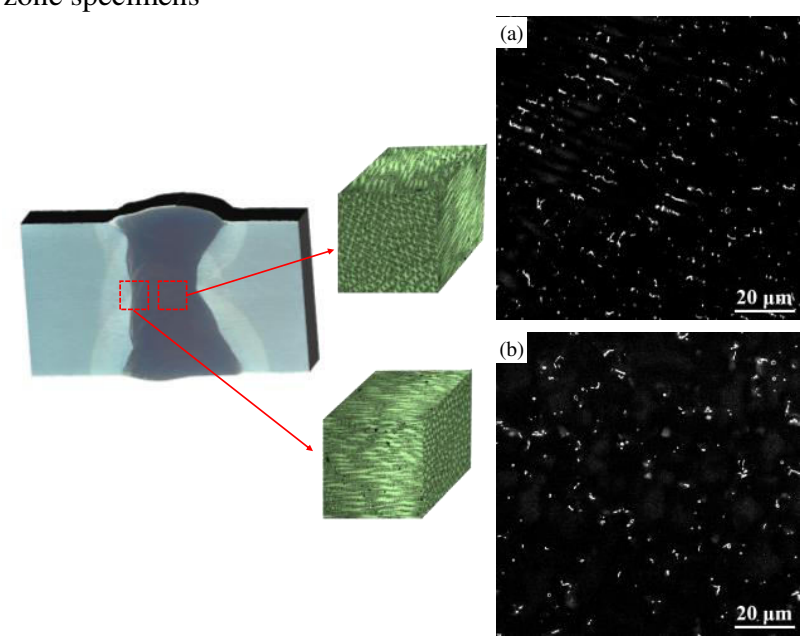

Fig. 7. Microstructure of (a) weld seam and (b) fusion zone 

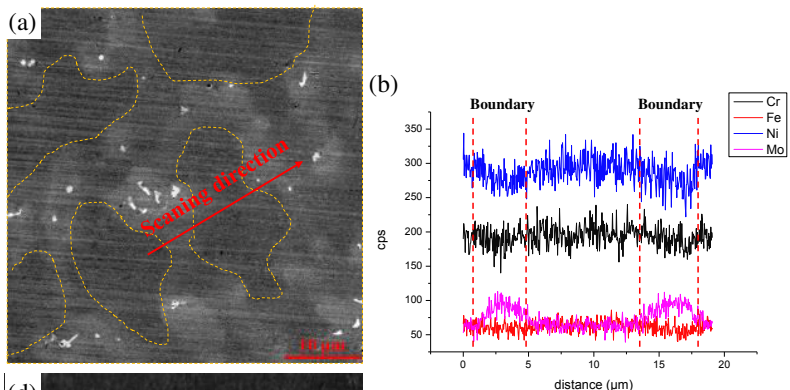

(c)
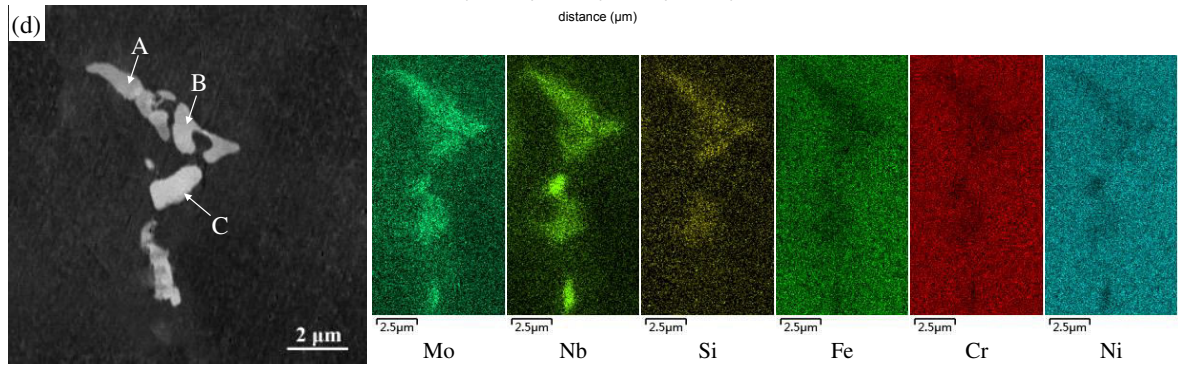

Fig. 8. Microstructure and EDS line scanning of dendritic cells perpendicular to the build direction : (a) the microstructure and scanning position, (b) the EDS line scanning profiles, (c) EDS point analysis of precipitated phase in (d), and (d) layered analysis of precipitated phase

\subsection{Microstructure characteristics}

Fig 7 showed the microstructure of the welded joint. The crystallizing morphology in weld seam was equiaxed dendrite, and it was columnar crystals in the fusion zone. The growth direction of austenite is along the temperature gradient. The average number of laves phases was computed by counting 3 zones of $0.1 \mathrm{~mm} \times 0.1 \mathrm{~mm}$ size randomly in appropriate areas (Fig 7 (a), Fig 7 (b)). The statistical results were $2.06 \times 10^{4} / \mathrm{mm}^{2}$ and $1.32 \times 10^{4} / \mathrm{mm}^{2}$ in fusion zone and weld seam, respectively. The number of fusion zone was $84.6 \%$ higher than that of weld seam.

As shown in Fig 8 (a), the bright area is dendritic cells boundary, while the dark area is in dendritic cells. The precipitated phases mainly distribute in dendritic cells boundary. By EDS line-scanning, it was observed that the content of Mo element in dendritic cells boundary is more than that in dendritic cells and the content of other elements $(\mathrm{Cr}, \mathrm{Fe}, \mathrm{Ni})$ in dendritic cells boundary are less than that in dendritic cells. The elements segregation is helpful to the formation of precipitated phase. EDS analysis also carried out to identify the types of precipitated phases as shown in Fig 8(c) and Fig 8(d). Relating to the out early research[16], it was sure that the precipitated phase conclude laves phases, which is always rod-shaped and rich in $\mathrm{Nb}$ and Mo.

\subsection{Crack propagation behavior}

Fig 9 shows the fatigue crack propagation path of LCF specimens tested at $296 \mathrm{~K}$ and $80 \mathrm{~K}$. At room temperature, most cracks propagated through dendrite grain, as shown in Fig 9 (a). The propagation path was straighter. Few cracks were observed to propagate along the dendrite boundary. Fig 9 (b) presented the crack propagation paths in cryogenic temperature. Most cracks passed through the grain boundaries even though there were only a few precipitates, meaning that the intergranular propagation mode was dominant. Crack passing through the precipitate phase became a priority at cryogenic temperature. As shown in Fig 11 (b), microvoids were observed in cryogenic-temperature specimens. At cryogenic temperature, the microvoids came from the fragmentation of precipitated phases under cyclic tension-compression loading. It reduced the resistance of crack propagation. It could inferred that laves phase when the microvoids distributed on the surface of sample, the microvoids would accelerate the formation of crack at cryogenic temperature.

As for CTOD specimens, the crack propagation path in stable crack propagation region of CTOD specimens were observed by using SEM with SBE mode as shown in Fig 10. 8 sections of every specimen were chosen to collect the laws of crack spreading. It could be assured that the main way of cracks in the region propagate at room temperature was to propagate through the grain boundary as shown in Fig 10(a). However, at low temperature. the commonest way is to propagate along the grain boundary as shown in Fig 10(b). No obvious microvoids were found in CTOD specimens.

It meant that the toughness of grain boundary is higher than that in grain interior at room temperature, but it was just the opposite at low temperature. The $\gamma$ austenite with fcc crystal structure has not embrittlement temperature and low temperature restrains the deformation of weld metal, so the precipitated phases are the main reasons for fracture toughness decrease at low temperature. Which leads to the fracture toughness of both types of weld is lower at that at low temperature. The more precipitated phases had, the lower toughness had. It is clear that the effect of precipitated number on the fracture at room temperature is greater than that at low temperature. 

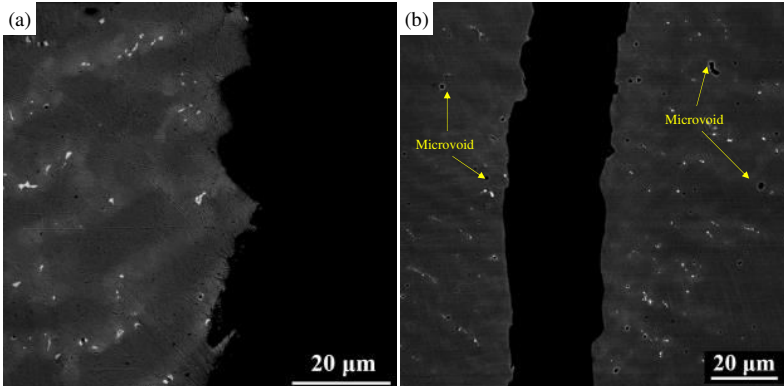

Fig. 9. Fatigue crack propagation path of LCF specimens at (a) $296 \mathrm{~K}$ and (b) $80 \mathrm{~K}$
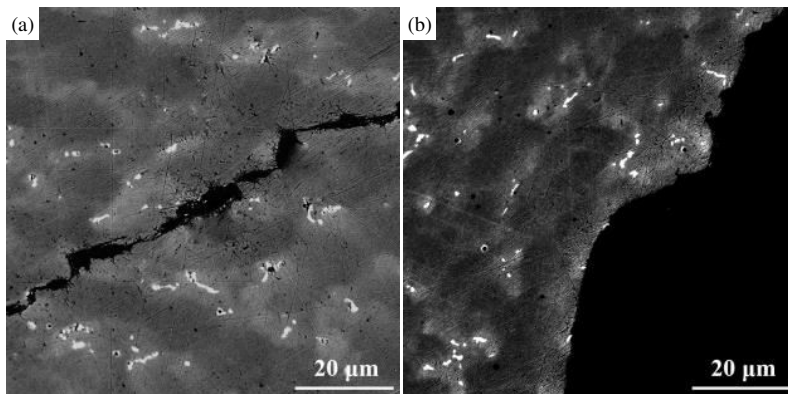

Fig. 10 crack propagation path in stable crack propagation region of CTOD specimens at (a) $296 \mathrm{~K}$ and (b) $80 \mathrm{~K}$

\subsection{Facture morphology characteristics}

It is recognized that fatigue fracture of LCF specimen is made up of three regions: crack initiation area (CIA), crack propagation area (CPA) and final rupture area (FRA). The fracture morphology of CIA and CPA region were observed by scanning electron microscopy (SEM). It was found that the cracks in specimens tested at room temperature initiated almost from the surface (Fig 11). The crack initiation area of low temperature joint was from the surface as well, which was because of the incision and stress concentration at the surface Fig 11(c), (Fig 11(d)).

Fig 12 shows the SEM of the crack propagation area of specimens under total strain amplitudes. It is found that fatigue striations, caused by repeated plastic blunting-sharpening process [19], were observed in the crack propagation area of all specimens. Second cracking was found only in cryogenic temperature specimens. Beside of fatigue striations, cleavage river pattern and extrusion ridges were found in all specimens, which mean that the crack propagation area of all specimens were ductile-brittle mixed fractures. The distance of striations increased with the total strain amplitudes. It was mostly the same at cryogenic temperature. It was because that the plastic strain amplitude increased with the increase of total strain amplitude.

As shown in Fig 13, the fracture morphology in $\mathrm{SCP}$ region of representative CTOD specimens were examined by scanning electron microscopy (SEM). For weld seam specimens, the dimples at room-temperature specimens, were bigger and deeper than that in corresponding low-temperature specimens, as well as fusion area specimen as shown in Fig 13 (a) and Fig 13 (b). It's in accordance with the measured values of
CTOD. The low-temperature specimens still showed ductile fracture characteristics to some extent since some dimples were found. It was also found that the dimples in weld seam were obviously shallower than that in fusion zone, and the cleavage characteristic appeared locally, as shown in Fig 13 (c). With the decrement of testing temperature, the cleavage characteristic of fracture surface increased, as shown in Fig 13 (d). The differences of fracture surface was consistent with the CTOD values.
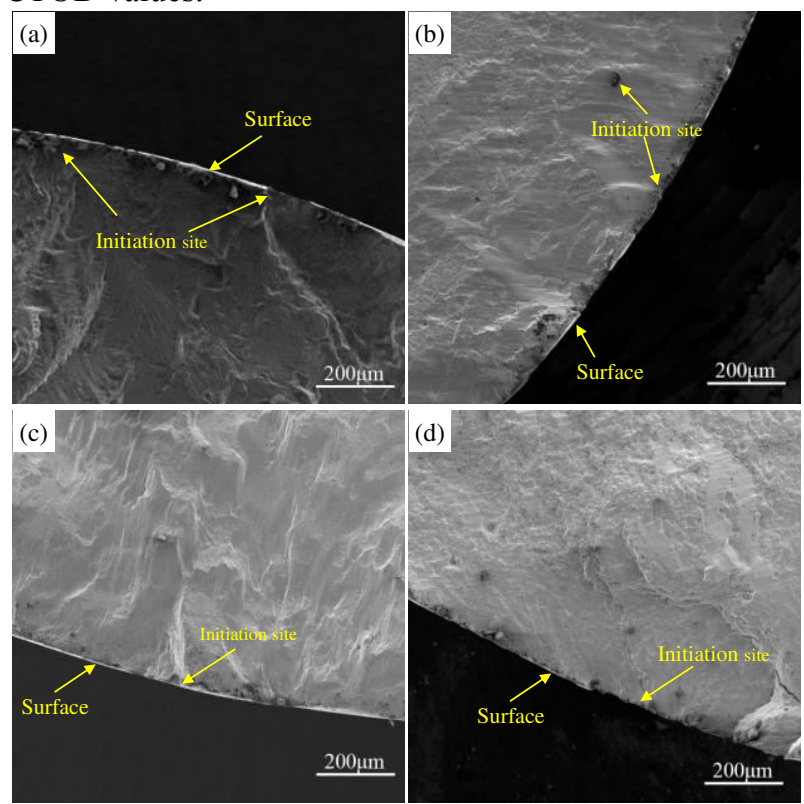

Fig. 11. The crack initiation area of all specimens: (a), (b) at room temperature and (c), (d) at cryogenic temperature
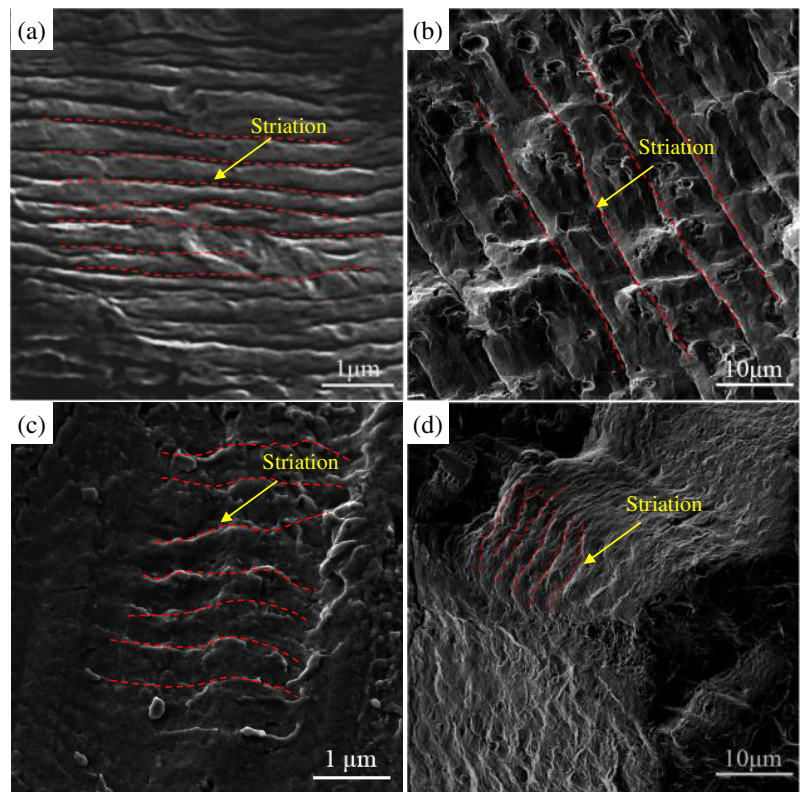

Fig. 12. The crack propagation area of specimen under different temperatures and total strain amplitudes: (a) , (b) $0.40 \%$ and $0.60 \%$ at room temperature, (c) , (d) $0.40 \%$ and $0.60 \%$ at cryogenic temperature 

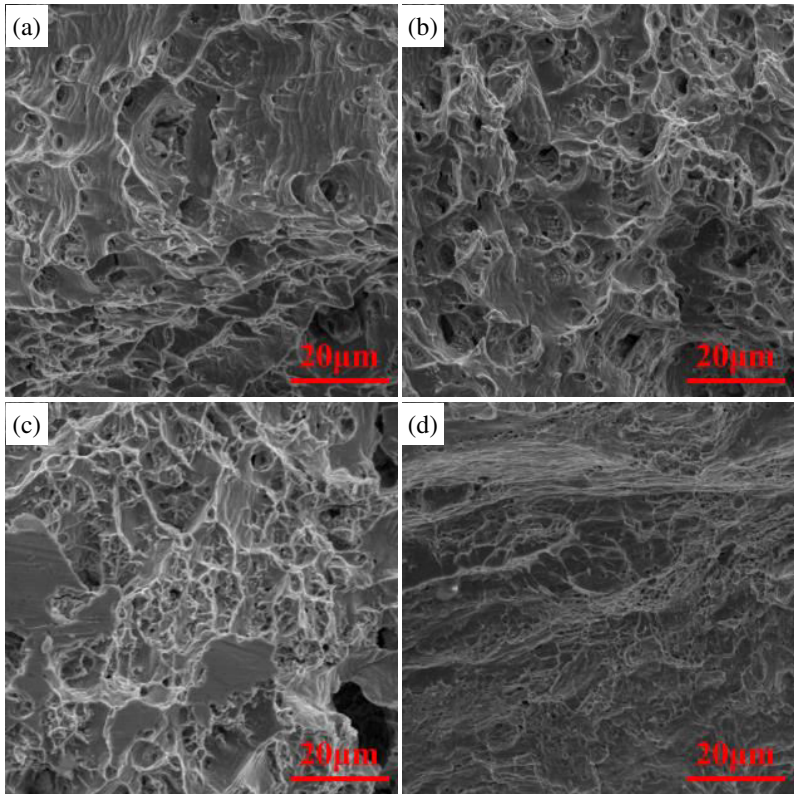

Fig. 13. The fracture morphologies in stable crack propagation region of CTOD specimens: (a), (b) weld seam specimen tested at room temperature and low temperature, and (c), (d) funsion zone specimen tested at room temperature and low temperature

\section{Conclusions}

1. At cryogenic temperature, under the same total strain amplitude, the fatigue life of $9 \% \mathrm{Ni}$ steel welded joint increased, due to the higher fatigue strength. Most fracture initiation of joints located in fusion area at room temperature, while it occurred in weld seam at cryogenic temperature.

2. The fracture toughness of weld metals was tested using CTOD at room temperature $(296 \mathrm{~K})$ and at low temperature $(80 \mathrm{~K})$, respectively. Experimental results showed that the weld seam with less precipitates had higher CTOD values no matter the testing temperature.

3. The effect of precipitated phase was the true reason for these behavior. The fatigue cracks propagated in transgranular mode at room temperature, ultimately, and intergranular mode at low temperature in both LCF specimens and CTOD specimens.

This work was supported by the Ministry of Industry and Information Technology of China under the project of LNG shipbuilding.

\section{References}

1. Min Z, Ming Z, Jihong LI. Development and performance analysis of self-shielded flux cored wire for $9 \% \mathrm{Ni}$ steel. Transactions of the China Welding Institution. 2015.

2. Zhao S, Xie X, Smith GD, Patel SJ. Research and Improvement on structure stability and corrosion resistance of nickel-base superalloy INCONEL alloy 740. MATER DESIGN. 2006;27:1120-7.

3. Chai G, Liu P, Zhou N, Frodigh J. Low and High Cycle Fatigue Behavior of Nickel-base Alloy at
High Temperatures. Procedia Engineering. 2013;55:671-6.

4. Mataveli Suave L, Cormier J, Bertheau D, Villechaise P, Soula A, Hervier Z, et al. High temperature low cycle fatigue properties of alloy 625. Materials Science and Engineering: A. 2016;650:161-70.

5. Li S, Ping L. Low-Cycle Fatigue Behavior of a Nickel Base Single Crystal Superalloy at High Temperature. RARE METAL MAT ENG. 2015;44:288-92.

6. Brien V, Décamps B. Low cycle fatigue of a nickel based superalloy at high temperature: deformation microstructures. Materials Science and Engineering: A. 2001;316:18-31.

7. Praveen KVU, Singh V. Effect of heat treatment on Coffin - Manson relationship in LCF of superalloy IN718. Materials Science and Engineering: A. 2008;485:352-8.

8. Silva CC, Miranda HCD, Motta MF, Farias JP, Afonso CRM, Ramirez AJ. New insight on the solidification path of an alloy 625 weld overlay. Journal of Materials Research and Technology. 2013;2:228-37.

9. Ono Y, Yuri T, Sumiyoshi H, Takeuchi E, Matsuoka S, Ogata T. High-Cycle Fatigue Properties at Cryogenic Temperatures in INCONEL 718 Nickelbased Superalloy. MATER TRANS. 2004;45:342-5.

10. SOON IL KWON SHBJ. Characterization of the Microstructures and the Cryogenic Mechanical Properties of Electron Beam Welded Inconel 718. METALLURGICAL AND MATERIALS TRANSACTIONS A: Physical Metallurgy and Materials Science. 2016;47:777-87.

11. Qin XZ, Guo JT, Yuan C, Chen CL, Hou JS, Ye HQ. Decomposition of primary MC carbide and its effects on the fracture behaviors of a cast Ni-base superalloy. Materials Science and Engineering: A. 2008;485:74-9.

12. Institution BS. Iso/cd 12106 - Metallic Materials Fatigue Testing Axial Strain - Controlled Method.

13. Mostaghel N, Byrd RA. Inversion of Ramberg Osgood equation and description of hysteresis loops. INT J NONLIN MECH. 2002;37:1319-35.

14. British Standard Institution. BS7448:Part2:1997. Method for Determination of KIC、Critical CTOD and Critical $\mathbf{J}$ Values of Welds in Metallic Materials[S]..

15. British Standard Institution. BS7448:Part1:1991. Method for Determination of KIC、Critical CTOD and Critical J Values of Metallic Materials[S]..

16. Mu W, Li Y, Cai Y, Wang M. Cryogenic fracture toughness of $9 \% \mathrm{Ni}$ steel flux cored arc welds. J MATER PROCESS TECH. 2018;252:804-12.

17. Bond DM, Zikry MA. Microstructural Modeling of Intergranular Fracture in Tricrystals With Random Low- and High-Angle Grain Boundaries. 2017.

18. Wang Z, Sun S, Wang B, Shi Z, Fu W. Importance and role of grain size in free surface cracking prediction of heavy forgings. Materials Science and Engineering: A. 2015;625:321-30. 
19. Fedelich B, Kiyak Y, Toulios M, Voudouris G. Modelling of high temperature crack growth in a single crystal superalloy under low cycle fatigue loading. International Conference on Low Cycle Fatigue2008. 